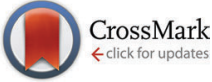

Cite this: Phys. Chem. Chem. Phys., 2016, 18, 23320

Received 18th June 2016, Accepted 1st August 2016 DOI: $10.1039 / \mathrm{c} 6 \mathrm{cp} 04280 \mathrm{e}$

www.rsc.org/pccp

\section{Quantitative determination of activation energies in mechanochemical reactions $\dagger$}

\author{
Franziska Fischer, ${ }^{a b}$ Klaus-Jürgen Wenzel, ${ }^{a}$ Klaus Rademann ${ }^{\mathrm{ab}}$ and \\ Franziska Emmerling*a
}

\begin{abstract}
Mechanochemical reactions often result in 100\% yields of single products, making purifying procedures obsolete. Mechanochemistry is also a sustainable and eco-friendly method. The ever increasing interest in this method is contrasted by a lack in mechanistic understanding of the mechanochemical reactivity and selectivity. Recent in situ investigations provided direct insight into formation pathways. However, the currently available theories do not predict temperature $T$ as an influential factor. Here, we report the first determination of an apparent activation energy for a mechanochemical reaction. In a temperaturedependent in situ study the cocrystallisation of ibuprofen and nicotinamide was investigated as a model system. These experiments provide a pivotal step towards a comprehensive understanding of milling reaction mechanisms.
\end{abstract}

Mechanochemistry is one of the oldest synthesis methods. The roots can be traced back into the 4th century B.C., where mercury was gained by grinding cinnabar with acetic acid. ${ }^{1}$ In the 19th century, mechanochemistry was established by the work of Carey Lea who showed that grinding reactions can yield products different from the outcome of thermally activated reactions. $^{2,3}$ Based on the four different energetic activation possibilities, Ostwald later classified mechanochemistry as one of the four sub-disciplines of physical chemistry next to electrochemistry, photochemistry, and thermochemistry. ${ }^{4}$ In recent years, mechanochemical reactions have found an ever growing range of applications, mainly by providing an eco-friendly alternative to more solvent and energy consuming reaction pathways. ${ }^{5-10}$ Besides pure neat grinding, the variability of the method can be tremendously enhanced by addition of just a small amount of liquids (liquid assisted grinding, LAG), ionic liquids (ionic liquid assisted grinding, ILAG), or polymers (polymer assisted grinding POLAG). ${ }^{11-13}$ Extensive solvent-screenings in the LAG process can lead to polymorphic compounds or new products. ${ }^{14-17}$ With the increasing use of mechanochemistry there is an increasing need to understand the mechanisms of mechanochemical reactions. Mechanical activation provokes mass transport processes different from those working under thermal activation, resulting in different physical and chemical behaviour of solids. ${ }^{18}$ Theoretical approaches like the magma plasma theory and the hot spot theory emphasise

\footnotetext{
${ }^{a}$ BAM Federal Institute for Materials Research and Testing, R.-Willstätter-Str. 11, 12489 Berlin, Germany. E-mail: franziska.emmerling@bam.de

${ }^{b}$ Humboldt-Universität zu Berlin, B.-Taylor-Str. 2, 12489 Berlin, Germany

$\dagger$ Electronic supplementary information (ESI) available: Experimental data, Powder diffraction and Raman data. See DOI: 10.1039/c6cp04280e
}

the occurrence of steep local temperature rises which initiates the mechanochemical conversion. ${ }^{19,20}$ A generally applicable theory on mechanochemical mechanisms is yet not available. Studies of grinding reactions suggest that the processes cannot be described by a universal mechanism. The interplay and entanglement of different mechanisms have to be considered with respect to the nature of the reactants (inorganic, metalorganic, or organic). Molecular diffusion, eutectic formation, and crystallization mediated by an amorphous phase are primarily discussed for the mechanosynthesis of organic compounds. ${ }^{21,22}$ Certainly, experimental evidence is needed for a profound understanding of underlying mechanisms. From the experimental side, ex situ investigations were performed in first attempts to elucidate mechanistic pathways. Small amounts of sample were extracted from the reaction jar and immediately investigated using Raman spectroscopy or powder X-ray diffraction (XRD). ${ }^{17,23-27}$ $\mathrm{XRD}$ is a central method utilized to study formation of crystalline solids, phase transitions, and polymorphic interconversions in real time. A prerequisite for XRD is the existence of a crystalline solid consisting of several unit cells, typically more than ten per edge. In order to elucidate the structure of transient crystalline or amorphous intermediates, additional techniques are required to monitor their existence. Raman spectroscopy allows in situ monitoring of crystal formation, amorphous stages, and of the transformation from one polymorph into another one. These pioneering experiments provided valuable mechanistic insights. The formation of intermediates and stepwise processes were monitored and the reaction rates were evaluated. However, it became clear that ex situ studies have limitations. Depending on the time-steps chosen for sampling, transient phases might be missed, and interrupted reactions could result in products 
different from those in continuous milling reactions, but in general have severe limitations. ${ }^{28,29}$ Very recently, in situ investigations of mechanochemical milling reactions have been introduced. Synchrotron X-ray diffraction and Raman spectroscopy and a tandem combination thereof were employed to obtain previously inaccessible data on milling reactions. ${ }^{30-34}$ Without interrupting the milling process, a real-time characterization of crystalline solids including transformations, intermediates, and the occurrence of amorphous phases is possible. These in situ investigations circumvent the restrictions of a stepwise analysis. Fundamental information such as reaction mechanisms and pathways were available using the in situ methodology. ${ }^{35-40}$

This methodology paves the way for kinetic investigations of mechanochemical reactions. Previous studies state that the kinetics of mechanochemically activated processes is governed not by time (as in classical kinetics) but by the total number of collisions. ${ }^{41-44}$ In connection to that it is discussed that the mechanochemical activation energy is the minimum of mechanical energy input to activate the transformation process. ${ }^{18}$ However, many mysteries related to the mechanochemical reactivity still wait for their discovery. Among those are the very nature of the mechanochemical activation itself, the impact of temperature on the reactivity, and the interplay between input energy and frictional heating. ${ }^{45-47}$ Important information remains elusive: the temperature-dependence of reaction rates and the determination of the activation energy.

To acquire these data, we developed a coolable grinding jar for precisely adjusting the temperature during milling allowing temperature-dependent in situ analyses using Raman spectroscopy. The subpart of the vessel consists of a stainless steel jar, fused with a cooling coil. The temperature can be adjusted tuning the pressure of the cooling nitrogen stream. A thermocouple connected to the grinding jar records the temperature during the milling process. Any temperature fluctuation is compensated by adjusting the pressure of the nitrogen stream. The temperature can be kept constant within $\pm 1 \mathrm{~K}$. The top part of the jar consists of a transparent Macrolon hemisphere. This material has sufficient mechanical strength and is transparent for enabling in situ Raman measurements. The cocrystallisation of ibuprofen and nicotinamide was chosen as a model system. Cocrystals are stoichiometric two- or more-component crystalline phases of neutral molecules stabilized via intermolecular interactions including halogen bonds, hydrogen bonds, and $\pi-\pi$-stacking. ${ }^{48,49}$ Cocrystallisation of a distinct compound with an appropriate coformer can change its physicochemical properties without altering its chemical effect. ${ }^{50-52}$ Nowadays, mechanochemistry is an established synthesis method for cocrystals. The cocrystallisation of ibuprofen (ibu) and nicotinamide (na) is a suitable model system for in situ investigations using Raman spectroscopy (see Fig. 1.). The ibu:na cocrystal was thoroughly characterized and can be obtained either by liquid assisted grinding (LAG) or neat grinding. ${ }^{53-55}$ The Raman spectra of the reactants and the cocrystal are shown in Fig. 2. The Raman bands selected for the temperature-dependent milling analysis were chosen carefully to avoid superimposition of the spectra of the reaction compounds among each other and with those of the

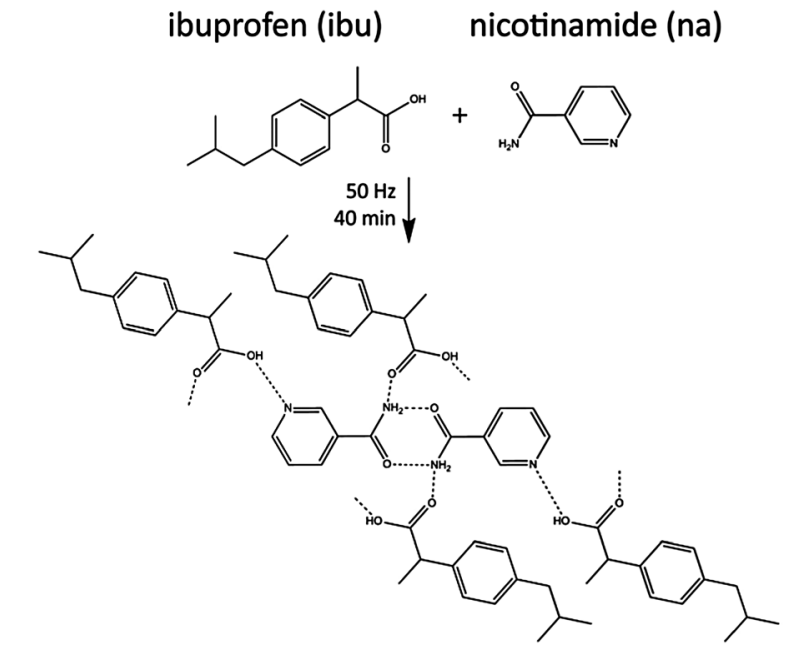

Fig. 1 For the cocrystallisation ibu and na were ground together for $40 \mathrm{~min}$ at $50 \mathrm{~Hz}$ in a conventional vibration mill.

Macrolon jar (Fig. S10, $\mathrm{ESI}_{\dagger} \dagger$ ). In the spectrum of ibu the most suitable signals occur at $784 \mathrm{~cm}^{-1}$ and $820 \mathrm{~cm}^{-1}$ attributed to the deformation of the carbonyl group and the $\mathrm{C}-\mathrm{H}$ bending vibration of the aromatic ring. ${ }^{56}$ Two characteristic absorption bands can be identified for the coformer na. The intensive Raman band at $1042 \mathrm{~cm}^{-1}$ is associated with the stretching within the aromatic ring. The second absorption band at $1391 \mathrm{~cm}^{-1}$ is attributed to the stretching mode between the carbonyl carbon atom and the nitrogen atom of the amino group. ${ }^{57}$ The reaction rate of the cocrystal formation was investigated at six different temperatures: $282 \mathrm{~K}, 286 \mathrm{~K}, 290 \mathrm{~K}, 294 \mathrm{~K}, 298 \mathrm{~K}$, and $302 \mathrm{~K}$. The reactants, the jar, and the milling balls were pre-cooled ensuring the requested experiment temperature directly from the start of the experiment. The neat grinding process was performed for $40 \mathrm{~min}$ at $50 \mathrm{~Hz}$ in a commercial vibration mill (Pulverisette 23, Fritsch, Germany). During the reaction no intermediates could be observed.

The Raman spectra were recorded with an acquisition time of $5 \mathrm{~s}$ and 5 accumulations during grinding. A schematic presentation of the setup is depicted in Fig. 3. Plotting the Raman intensities of the absorption bands at $784 \mathrm{~cm}^{-1}, 820 \mathrm{~cm}^{-1}$, $1042 \mathrm{~cm}^{-1}$, and $1391 \mathrm{~cm}^{-1}$ according to a first-order reaction leads to a linear fit as depicted in Fig. 4a. The obtained temperaturedependent reaction rate constants are depicted in Fig. $4 \mathrm{~b}$ and summarized in Table S1 (ESI $\dagger$ ).

All rate constants reveal similar values at the same temperature. As expected, the absolute values of the rate constants increase with higher temperatures. Therefore, it can be assumed that the mechanochemical synthesis of the ibu:na cocrystal follows the Arrhenius law $k=A \mathrm{e}^{-\frac{E_{\mathrm{a}}}{(R T)}} \cdot{ }^{58-60}$ Here, $A$ represents a preexponential factor, which is connected to the number of collisions per time in the reaction, $E_{\mathrm{a}}$ describes the activation energy of the reaction and $R$ is the universal gas constant. Collisions in the grinding jar lead to local temperature increase. Therefore, the experimentally adjusted temperatures of the grinding jar have to be regarded as nominal. For the evaluation based on the Arrhenius law the exact temperature values can be neglected and 
a

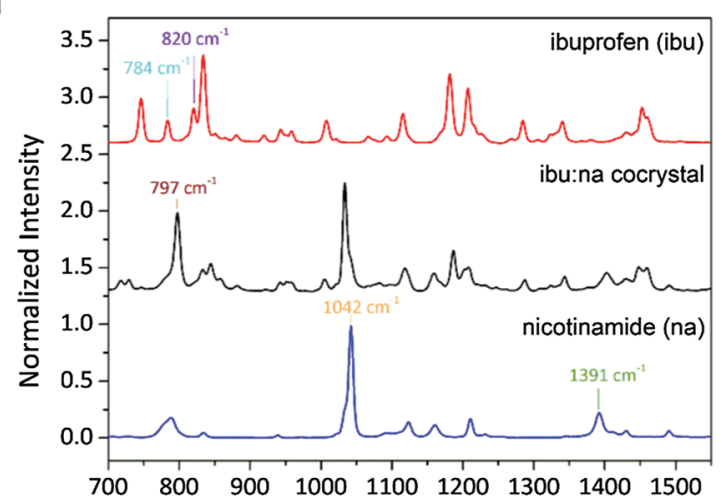

b

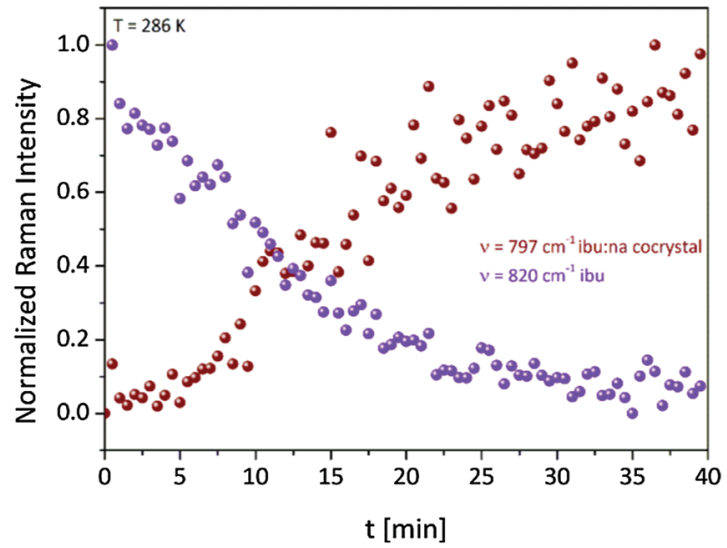

C

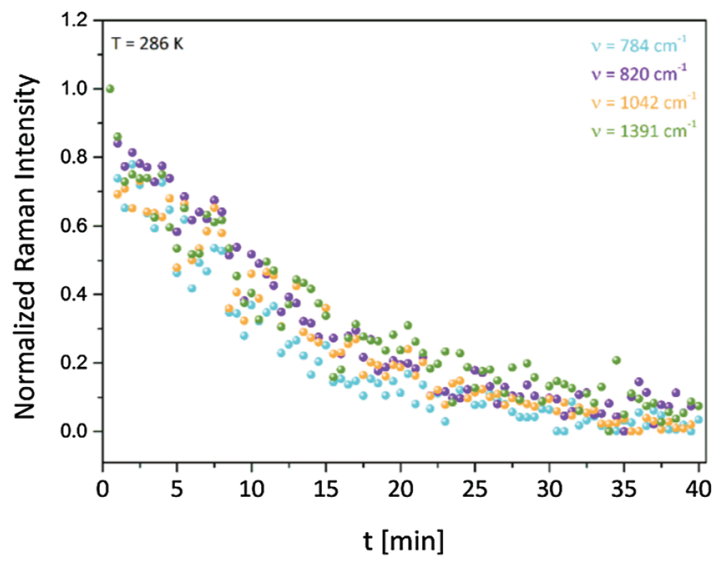

Fig. 2 In situ investigation of a mechanochemical synthesis under controlled temperature. (a) Raman spectra of the ibu:na cocrystal (black) and the reactants ibu (red) and na (blue). (b) Time-resolved investigation of the reaction process followed by the decrease of the Raman band of the reactant ibu $\left(820 \mathrm{~cm}^{-1}\right.$, violet) and the increase of the Raman band of the product $\left(797 \mathrm{~cm}^{-1}\right.$, dark red) at $T=286 \mathrm{~K}$. (c) The time-resolved change of Raman intensities of selected absorption bands of ibu $\left(784 \mathrm{~cm}^{-1}\right.$, light blue and $820 \mathrm{~cm}^{-1}$, violet) and na $\left(1042 \mathrm{~cm}^{-1}\right.$, orange and $1391 \mathrm{~cm}^{-1}$, green) during the milling process.

the slope of the rate has to be considered. Based on the Arrhenius plot (Fig. S12, eqn (S2), ESI $\dagger$ ) the activation energy of the mechanochemical cocrystallisation of ibu with na amounts to $15 \pm 6 \mathrm{~kJ} \mathrm{~mol}^{-1}$. Since the local temperatures within the jar cannot be controlled, the definition of an exact activation energy is

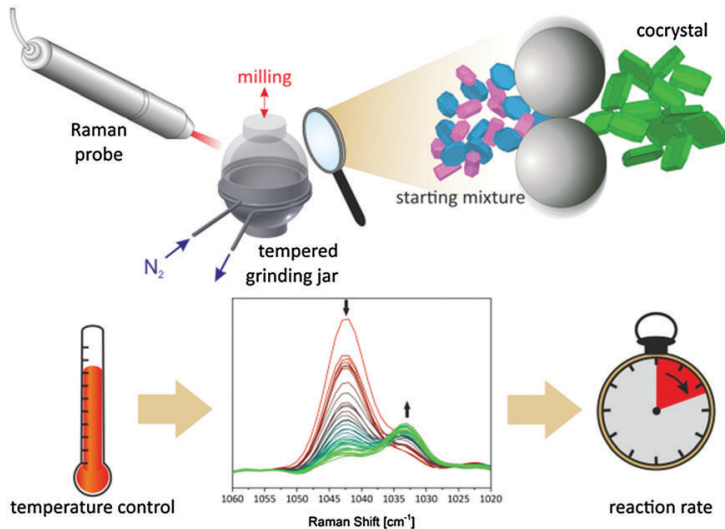

Fig. 3 Schematic of the real-time and in situ monitoring of a mechanochemical reaction using Raman spectroscopy.

a

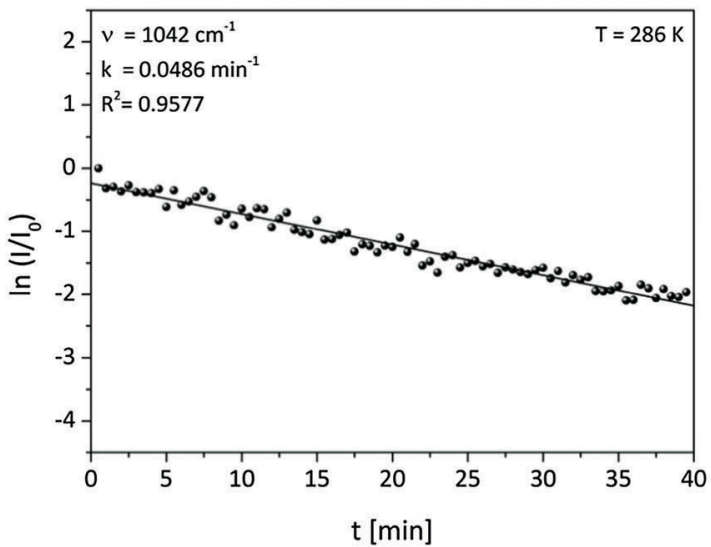

b

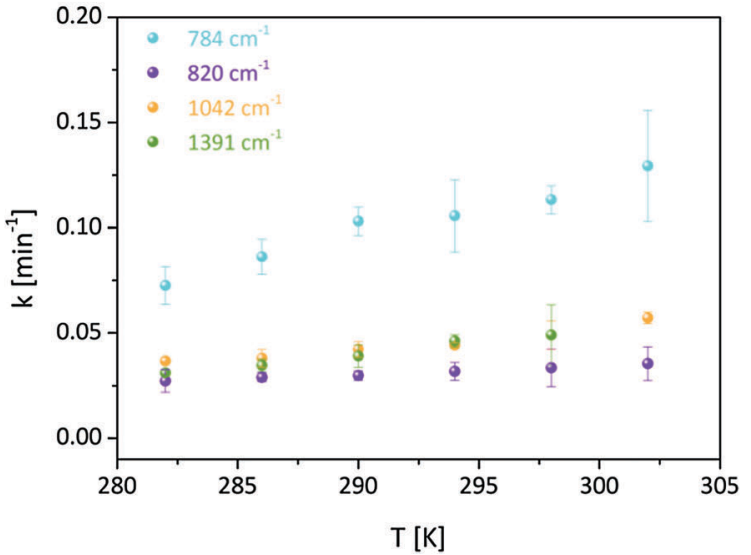

Fig. 4 (a) Plot of the Raman intensities according to a first-order reaction of the absorption band at $1042 \mathrm{~cm}^{-1}$ during the mechanochemical cocrystallisation of ibu with na at $286 \mathrm{~K}$. (b) Determined rate constants as a function of temperature of the mechanochemical ibu:na cocrystal syntheses.

difficult. Therefore, we refer to the experimental value as the apparent activation energy of the process. The low obtained activation barrier is a consequence of the reaction pathway. During cocrystallisation no chemical bonds have to be broken in order to form the new compound. After cocrystallisation, the na molecules form a $R_{2}^{2}(8)$-homodimer, which is extended via hydrogen 


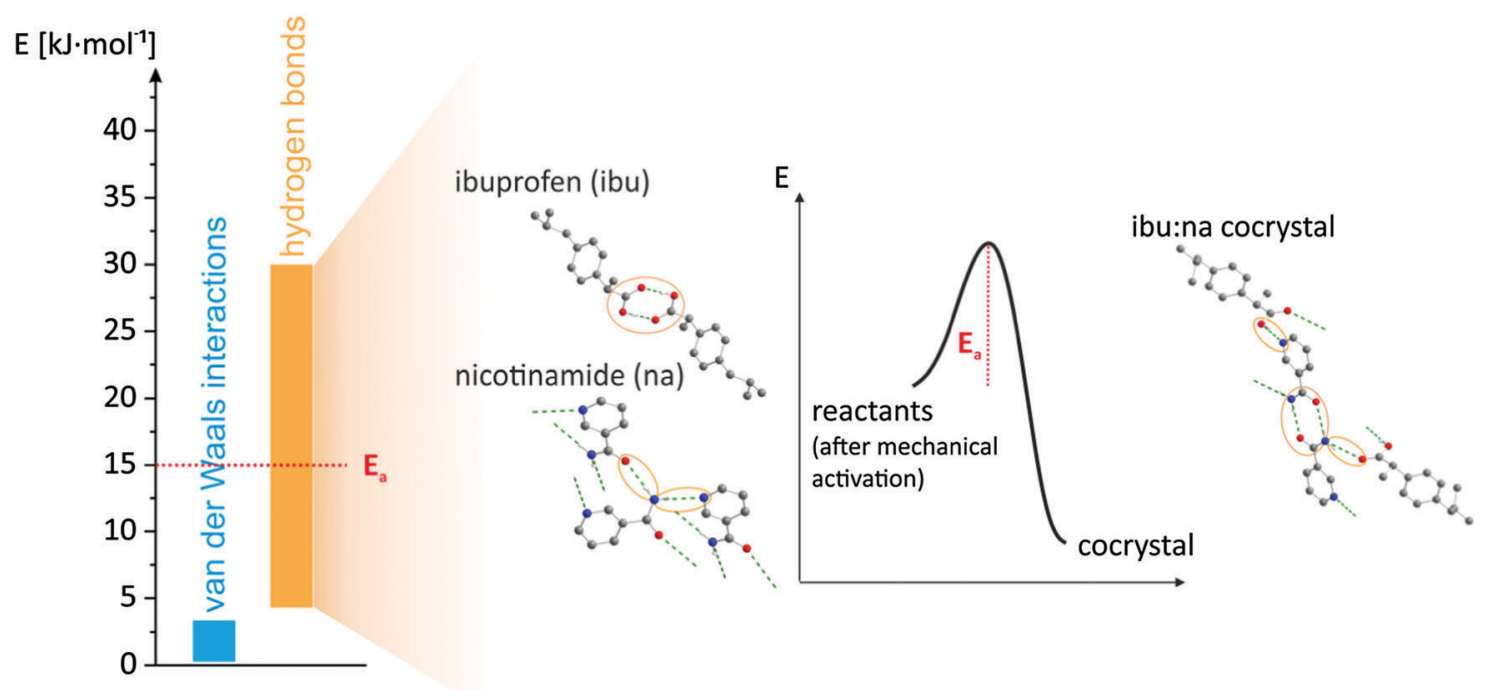

Fig. 5 Schematic presentation of the determined apparent activation energy (red line at $15 \mathrm{~kJ} \mathrm{~mol}^{-1}$ ) in the context of binding energies of relevant intermolecular forces.

bonds between the amino group of na and the carbonyl oxygen atoms of two ibu molecules. Additionally, the basic pyridine nitrogen atom of na interacts with the acidic oxygen atom of the carboxylic acid group of ibu. All interactions have to be formed in the cocrystallisation process, whereas all hydrogen bonds in the reactant species have to be broken. Typically, hydrogen bonds have bond energies between 4 and $30 \mathrm{~kJ} \mathrm{~mol}^{-1} .{ }^{61}$ Karki showed that the $R_{2}^{2}(8)$-homodimer of suberic acid has a calculated formation enthalpy of $15 \mathrm{~kJ} \mathrm{~mol}^{-1} .^{24}$ Based on the similar carbon backbone, it can be suggested that the formation enthalpy of the homodimer of ibu attains a similar value. In na, the synthon consists of only one hydrogen bond leading to the assumption that these interactions reveal a lower formation enthalpy. Comparing theoretical calculations with our experimental study, it can be concluded that the experimental determination of the apparent activation energy of the mechanochemical cocrystallisation leads to a reasonable value (see Fig. 5).

The existence of a thermally induced rate-determining step in the mechanochemical reaction is surprising. It shows clearly that the mechanochemical cocrystallisation combines mechanochemical activation with a thermochemical crystallisation process. Previous studies revealed that the mechanochemical cocrystallisation proceeds via a non-crystalline step such as an amorphous state, a eutectic, or a vapour phase. ${ }^{62}$ In the case of ibu and na the reaction via an amorphous intermediate is most probable. The cooled reaction conditions and the vapour pressure of the reactants exclude both other possibilities. Based on the results of this study, it can be assumed that the mechanical treatment of the reactants leads to an activation of the reaction through amor-phization. The thermally induced rate-determining step is the crystallization from the amorphous, activated intermediate. In the amorphous intermediate the interactions of the reactant molecules partially persist. These interactions have to be broken before the crystallization can proceed. Although this second step proceeds under thermochemical conditions, it is only possible through a mechanical activation. Therefore, this reaction step also belongs to mechanochemistry. Based on these results, we believe that more mechanochemical reactions as expected contain the described two steps of mechanical activation and thermochemical reaction.

\section{Conclusion and outlook}

The detailed nature in which chemistry is induced by the application of external mechanochemical forces can be understood by following a straightforward strategy. A first crucial step is the choice of a suitable model system. Secondly, combining the model system with a perfectly fitting in situ method reveals the secrets behind the mechanism and renders it transparent. Thirdly, by exploring the full parameter space, it is possible to falsify, verify, or extend the currently available models for interpreting mechanochemical reactions. The main approaches, including the magmaplasma and the hot-spot theory, do not consider the activation energy as a crucial factor. Here, the neat grinding synthesis of the ibuprofen:nicotinamide cocrystal in a ball mill was chosen as a model system. In situ Raman spectroscopy was selected as the analytical method, providing all the necessary structural information. The experiments were carried out in a coolable grinding jar allowing direct in situ Raman spectroscopic investigations. Determining the temperature-dependent cocrystallisation rate constants lead to an apparent activation energy of $15 \pm 6 \mathrm{~kJ} \mathrm{~mol}^{-1}$. For the first time, the activation barrier of a mechanochemically induced reaction was determined based on in situ Raman spectroscopy experiments. The benefits of temperature-dependent Raman studies are twofold: (i) yield curves of reactants and products can be recorded in situ, and (ii) fitting of kinetic models for various temperature deliver the quantitative value for the activation energy. We conclude that the recent development provides a first access to the influence 
of the ambient temperature on a milling reaction. The experimental layout is applicable for various types of milling reactions, including inorganic, metalorganic, and organic reactants. But these results lead not only to insights of mechanochemical reactions. This new knowledge will also affect other mechano-processes as dynamic condensation of DNA by compression-expansion processes or mechano-responsive luminescence. ${ }^{63,64}$ We foresee remarkable new mechanistic insights for the old method mechanochemistry.

\section{Experimental section}

\section{Experimental detail}

Ibuprofen, $\mathrm{C}_{13} \mathrm{H}_{18} \mathrm{O}_{2}$, (99\%, Alfa Aesar, Germany) and nicotinamide, $\mathrm{C}_{6} \mathrm{H}_{6} \mathrm{~N}_{2} \mathrm{O}$, ( $\geq 99.5 \%$, Sigma Aldrich, Germany) were purchased commercially and were used without further purification. Grinding was performed for all reactions (LAG and neat grinding) at $50 \mathrm{~Hz}$ for 40 min in a vibration mill (Pulverisette 23, Fritsch, Germany). In a typical experiment the coolable stainless-steel jar subpart of an $10 \mathrm{~mL}$ vessel was pre-tempered with two steel balls of $10 \mathrm{~mm}$ diameter and $4 \mathrm{~g}$ in mass. Afterwards, the pre-tempered reactants were added in a stoichiometric ratio of $1: 1$ into the vessel for a total load of $1 \mathrm{~g}$ ( $0.6281 \mathrm{~g}$ ibuprofen and $0.3719 \mathrm{~g}$ nicotinamide). The vessel was directly sealed with a Makrolon top part. The nitrogen stream was turned on $30 \mathrm{~s}$ before milling in order to reach the required temperature quickly after starting the milling process. The temperature of the jar was controlled in the range of $\pm 1 \mathrm{~K}$ by adjusting the nitrogen stream. The experiments were conducted at the following temperatures: $282 \mathrm{~K}, 286 \mathrm{~K}, 290 \mathrm{~K}, 294 \mathrm{~K}, 298 \mathrm{~K}$, and $302 \mathrm{~K}$. Each individual data point was multiply repeated.

\section{Raman spectroscopy}

Raman measurements were performed using a Raman RXN1 ${ }^{\mathrm{TM}}$ Analyser (Kaiser Optical Systems, France). The spectra were collected using a contactless probe head (working distance $6.0 \mathrm{~cm}$, spot size $1.0 \mathrm{~mm}$ ). Raman spectra were recorded with an acquisition time of $5 \mathrm{~s}$ and 5 accumulations. NIR excitation radiation at $\lambda=785 \mathrm{~nm}$ and an irradiation of $6.6 \mathrm{~W} \mathrm{~cm}^{-2}$ were performed.

\section{Powder X-ray diffraction (PXRD)}

The milling synthesis of the ibu:na cocrystal was verified by PXRD (Fig. S1, ESI $\dagger$ ). All PXRD experiments were carried out using a D8 diffractometer (Bruker AXS, Karlsruhe, Germany) in transmission geometry $\left(\mathrm{Cu}-\mathrm{K}_{\alpha 1}\right.$ radiation, $\lambda=1.54056 \AA$ ) .

\section{Notes and references}

1 L. Takacs, The Journal of the Minerals, Metals \& Materials Society, 2000, 52, 12-13.

2 L. Takacs, J. Mater. Sci., 2004, 39, 4987-4993.

3 L. Takacs, Bull. Hist. Chem., 2003, 28, 26-34.

4 P. Baláž, Mechanochemistry in Nanoscience and Minerals Engineering, Springer-Verlag, Berlin, Heidelberg, 2008, pp. 1-102.

5 M. C. Etter, Z. Urbanczyk-Lipkowska, M. Zia-Ebrahimi and T. W. Panunto, J. Am. Chem. Soc., 1990, 112, 8415-8426.
6 M. C. Etter and D. A. Adsmond, Chem. Commun., 1990, 589-591.

7 F. Toda, K. Tanaka and A. Sekikawa, Chem. Commun., 1987, 279-280.

8 A. O. Patil, D. Y. Curtin and I. C. Paul, J. Am. Chem. Soc., 1984, 106, 348-353.

9 M. R. Caira, L. R. Nassimbeni and A. F. Wildervanck, J. Chem. Soc., Perkin Trans. 2, 1995, 2213-2216.

10 V. R. Pedireddi, W. Jones, A. P. Chorlton and R. Docherty, Chem. Commun., 1996, 987-988.

11 N. Shan, F. Toda and W. Jones, Chem. Commun., 2002, 2372-2373.

12 T. Friščić, D. G. Reid, I. Halasz, R. S. Stein, R. E. Dinnebier and M. J. Duer, Angew. Chem., Int. Ed., 2010, 49, 712-715.

13 D. Hasa, G. S. Rauber, D. Voinovich and W. Jones, Angew. Chem., Int. Ed., 2015, 54, 7371-7375.

14 W. Yuan, T. Friščić, D. Apperley and S. L. James, Angew. Chem., Int. Ed., 2010, 49, 3916-3919.

15 N. Madusanka, M. D. Eddleston, M. Arhangelskis and W. Jones, Acta Crystallogr., Sect. B: Struct. Sci., Cryst. Eng. Mater., 2014, 70, 72-80.

16 A. V. Trask, W. D. S. Motherwell and W. Jones, Chem. Commun., 2004, 890-891.

17 F. Fischer, G. Scholz, S. Benemann, K. Rademann and F. Emmerling, CrystEngComm, 2014, 16, 8272-8278.

18 P. Baláž, M. Achimovičová, M. Baláž, P. Billik, Z. CherkezovaZheleva, J. M. Criado, F. Delogu, E. Dutková, E. Gaffet and F. J. Gotor, Chem. Soc. Rev., 2013, 42, 7571-7637.

19 F. P. Bowden and A. D. Yoffe, Fast reactions in solids, Academic Press, New York, 1958.

20 P. A. Thiessen, K. Meyer and G. Heinicke, Grundlagen der Tribochemie, Akademie-Verlag, Berlin, 1967.

21 K. Chadwick, R. Davey and W. Cross, CrystEngComm, 2007, 9, 732-734.

22 K. Lien Nguyen, T. Friscic, G. M. Day, L. F. Gladden and W. Jones, Nat. Mater., 2007, 6, 206-209.

23 S. Rehder, M. Klukkert, K. A. M. Löbmann, C. J. Strachan, A. Sakmann, K. Gordon, T. Rades and C. S. Leopold, Pharmaceutics, 2011, 3, 706-722.

24 S. Karki, T. Friščić and W. Jones, CrystEngComm, 2009, 11, 470-481.

25 D. Cinčić, T. Friščić and W. Jones, J. Am. Chem. Soc., 2008, 130, 7524-7525.

26 A. M. Belenguer, G. I. Lampronti, D. J. Wales and J. K. M. Sanders, J. Am. Chem. Soc., 2014, 136, 16156-16166.

27 L. Trobs and F. Emmerling, Faraday Discuss., 2014, 170, 109-119. 28 L. Takacs, Prog. Mater. Sci., 2002, 47, 355-414.

29 V. Strukil, L. Fabian, D. G. Reid, M. J. Duer, G. J. Jackson, M. Eckert-Maksic and T. Friscic, Chem. Commun., 2010, 46, 9191-9193.

30 T. Friščić, I. Halasz, P. J. Beldon, A. M. Belenguer, F. Adams, S. A. J. Kimber, V. Honkimäki and R. E. Dinnebier, Nat. Chem., 2013, 5, 66-73.

31 I. Halasz, A. Puškarić, S. A. J. Kimber, P. J. Beldon, A. M. Belenguer, F. Adams, V. Honkimäki, R. E. Dinnebier, B. Patel, W. Jones, V. Štrukil and T. Friščić, Angew. Chem., Int. Ed., 2013, 52, 11538-11541. 
32 I. Halasz, S. A. J. Kimber, P. J. Beldon, A. M. Belenguer, F. Adams, V. Honkimäki, R. C. Nightingale, R. E. Dinnebier and T. Friščić, Nat. Protoc., 2013, 8, 1718-1729.

33 D. Gracin, V. Štrukil, T. Friščić, I. Halasz and K. Užarević, Angew. Chem., Int. Ed., 2014, 126, 6307-6311.

34 L. Batzdorf, F. Fischer, M. Wilke, K. J. Wenzel and F. Emmerling, Angew. Chem., Int. Ed., 2014, 54, 1799-1802.

35 F. Fischer, G. Scholz, L. Batzdorf, M. Wilke and F. Emmerling, CrystEngComm, 2015, 17, 824-829.

36 M. Wilke, M. Klimakow, K. Rademann and F. Emmerling, CrystEngComm, 2016, 18, 1096-1100.

37 K. Užarević, I. Halasz and T. Friščić, J. Phys. Chem. Lett., 2015, 6, 4129-4140.

38 A. D. Katsenis, A. Puškarić, V. Štrukil, C. Mottillo, P. A. Julien, K. Užarević, M.-H. Pham, T.-O. Do, S. A. J. Kimber, P. Lazić, O. Magdysyuk, R. E. Dinnebier, I. Halasz and T. Friščić, Nat. Commun., 2015, 6, 6662.

39 F. Fischer, A. Heidrich, S. Greiser, S. Benemann, K. Rademann and F. Emmerling, Cryst. Growth Des., 2016, 16, 1701-1707.

40 M. Wilke, L. Batzdorf, F. Fischer, K. Rademann and F. Emmerling, RSC Adv., 2016, 6, 36011-36019.

41 F. Delogu and G. Cocco, J. Alloys Compd., 2007, 436, 233-240.

42 F. Delogu, Scr. Mater., 2008, 58, 126-129.

43 F. Delogu, Acta Mater., 2008, 56, 2344-2352.

44 F. Delogu, Acta Mater., 2011, 59, 2069-2074.

45 S. You, M.-W. Chen, D. D. Dlott and K. S. Suslick, Nat. Commun., 2015, 6, 1-7.

46 C. F. Burmeister and A. Kwade, Chem. Soc. Rev., 2013, 42, 7660-7667.

47 I. A. Tumanov, A. F. Achkasov, E. V. Boldyreva and V. V. Boldyrev, CrystEngComm, 2011, 13, 2213-2216.

48 C. B. Aakeröy and D. J. Salmon, CrystEngComm, 2005, 7, 439-448.
49 S. Aitipamula, P. S. Chow and R. B. H. Tan, CrystEngComm, 2012, 14, 2381-2385.

50 H. Xu, X. Duan, H. Li and C. Pei, RSC Adv., 2015, 5, 95764-95770.

51 A. V. Trask, W. D. S. Motherwell and W. Jones, Int. J. Pharm., 2006, 320, 114-123.

52 D. J. Good and N. Rodríguez-Hornedo, Cryst. Growth Des., 2009, 9, 2252-2264.

53 D. J. Berry, C. C. Seaton, W. Clegg, R. W. Harrington, S. J. Coles, P. N. Horton, M. B. Hursthouse, R. Storey, W. Jones, T. Friščić and N. Blagden, Cryst. Growth Des., 2008, 8, 1697-1712.

54 F. L. F. Soares and R. L. Carneiro, Cryst. Growth Des., 2013, 13, 1510-1517.

55 S. F. Alshahateet, Mol. Cryst. Liq. Cryst., 2010, 533, 152-161. 56 A. Jubert, M. L. Legarto, N. E. Massa, L. L. Tévez and N. B. Okulik, J. Mol. Struct., 2006, 783, 34-51.

57 M. Bakiler, O. Bolukbasi and A. Yilmaz, J. Mol. Struct., 2007, 826, 6-16.

58 S. Arrhenius, Über die Dissociationswärme und den Einfluss der Temperatur auf den Dissociationsgrad der Elektrolyte, Wilhelm Engelmann, Leipzig, 1889.

59 S. Arrhenius, Zeitschrift für Physikalische Chemie, 1889, 4, 226-248.

60 A. D. McNaught, Compendium of chemical terminology, Blackwell Science Oxford, 1997.

61 J. Jiang, Y. Zhao and O. M. Yaghi, J. Am. Chem. Soc., 2016, 138, 3255-3265.

62 T. Friščić and W. Jones, Cryst. Growth Des., 2009, 9, 1621-1637.

63 Y. Sagara, S. Yamane, M. Mitani, C. Weder and T. Kato, Adv. Mater., 2016, 28, 1073-1095.

64 Y. Yonamine, K. Cervantes-Salguero, K. Minami, I. Kawamata, W. Nakanishi, J. P. Hill, S. Murata and K. Ariga, Phys. Chem. Chem. Phys., 2016, 18, 12576-12581. 